\title{
Posterior Urethral Polyp: First Holmium-YAG Laser Ablation on a 3-Month-Old Infant
}

\author{
Fatih Ozkaya, MD, Ercument Keskin, MD,2 Turgut Yapanoglu, MD, Senol Adanur, MD, \\ Tevfik Ziypak, MD, Mehmet Sefa Altay, Dr, and Yılmaz Aksoy, MD ${ }^{3}$
}

\begin{abstract}
Background: Urethral polyps are rare benign pathologies seen in the male posterior urethra, more frequently originating from verumontanum. In this article, we aimed to discuss diagnosis and treatment of a urethral polyp causing hematuria and urinary infection in a 3-month-old male infant. This is the first case in the literature in which a urethral polyp is treated with Holmium yttrium-aluminum-garnet (YAG) laser.

Case Presentation: The patient was a 3-month-old male infant, and complains were hematuria and crying during micturition. Ultrasonography and voiding cystourethrogram were used for diagnosis. Urethral polyp was observed on urethrocystoscopy. Ablation was performed with a newborn cystoscope.

Conclusion: Urethral polyp can cause hematuria and urinary obstruction and should be considered in the differential diagnosis of pathologies such as posterior urethral valve and cecoureterocele that could cause infravesical obstruction. Holmium-YAG laser is a good choice of treatment with easy application possibilities using a newborn cystoscope, especially for newborns and infants who have thin urethra.
\end{abstract}

\section{Introduction and Purpose}

A LTHOUGH BENIGN, rare urethral polyps seen in the male posterior urethra cause important morbidity as they cause infravesical obstruction. Urinary infection, acute urinary retention, bilateral ureterohydronephrosis, and hematuria are some of the morbidities. ${ }^{1}$ Polyps are situated in the fibromuscular tissue and covered with transitional epithelium. Posterior urethral polyp causing bilateral pelvicaliceal system dilation and hematuria in a 3-month-old male infant is discussed in this article.

\section{Case Report}

A 3-month-old infant was brought to the pediatric urology clinic by his parents with complaints of hematuria and crying during micturition. It was stated that no specific findings were observed during fetal ultrasonography. Routine biochemical tests and complete blood count values were within normal ranges. No other findings besides hematuria and leukocyturia were observed in the complete urinalysis. Trabeculation in the bladder wall and a $25 \times 27 \mathrm{~mm}$ iso-echogenous lobulized mass protruding from the bladder neck toward bladder lumen were observed on the urinary system by ultrasonography. The mean bladder wall thickness was $5.2 \mathrm{~mm}$. Furthermore, mild ectasia was observed in the bilateral pelvicaliceal system. A bladder filling defect was observed on the voiding cystourethrogram (Fig. 1). Urethral polyp with dimensions of $3 \times 2 \mathrm{~cm}$ protruding toward the bladder lumen from the posterior wall of the urethra was observed on urethrocystoscopy (Fig. 2). The polyp was ablated with Holmium yttriumaluminum-garnet (YAG) laser using $272 \mu \mathrm{m}$ laser probe in the same session (Fig. 3). Laser mode, power, and frequency settings were ablation, $0.8 \mathrm{~J}, 10 \mathrm{~Hz}$, respectively. The polyp that was dropped into the bladder was removed as a whole piece using foreign body forceps. It was put inside formaldehyde solution and sent to the pathology laboratory. Surgical circumcision was performed because of phimosis during the same session. The transurethral drain was removed at the postoperative 8th hour and the patient was observed to spontaneously urinate with pressure. The patient was

${ }^{1}$ Department of Urology, Erzurum Regional Training and Research Hospital, Erzurum, Turkey.

${ }^{2}$ Department of Urology, Mengucekgazi Training and Research Hospital, Erzincan University, Erzincan, Turkey.

${ }^{3}$ Department of Urology, Ataturk University Medical Faculty, Erzurum, Turkey.

(C) Fatih Ozkaya et al. 2016; Published by Mary Ann Liebert, Inc. This Open Access article is distributed under the terms of the Creative Commons License (http://creativecommons.org/licenses/by/4.0), which permits unrestricted use, distribution, and reproduction in any medium, provided the original work is properly credited. 


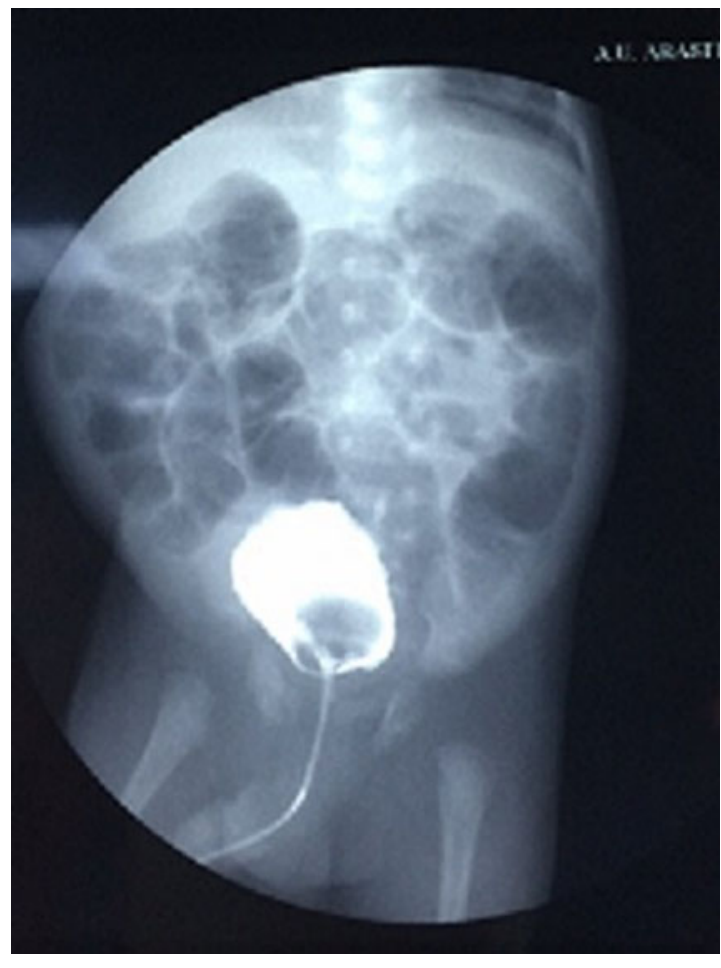

FIG. 1. Voiding cystourethrogram.

discharged. No dilation was observed in the kidneys and the bladder was normal on the control urinary system ultrasonography examination after 1 week. Pathology analysis reported as "squamous metaplasia," unlike expected (Fig. 4). Therefore, it was decided that control urethrocystoscopy should be performed 6 months later.

\section{Discussion}

Posterior urethral polyps are benign lesions that are rarely seen in males, are most frequently accepted to originate from verumontanum, covered with transitional epithelium, and thought to originate from mesonephric duct remnant. ${ }^{1,2}$ Symptoms frequently include hematuria, obstructive micturition symptoms, urinary retention, and dysuria. ${ }^{3,4}$ Imaging techniques, urinary system ultrasonography, voiding cystourethrogram, and urethrocystoscopy are performed in addition to routine laboratory tests for diagnosis. Transure-

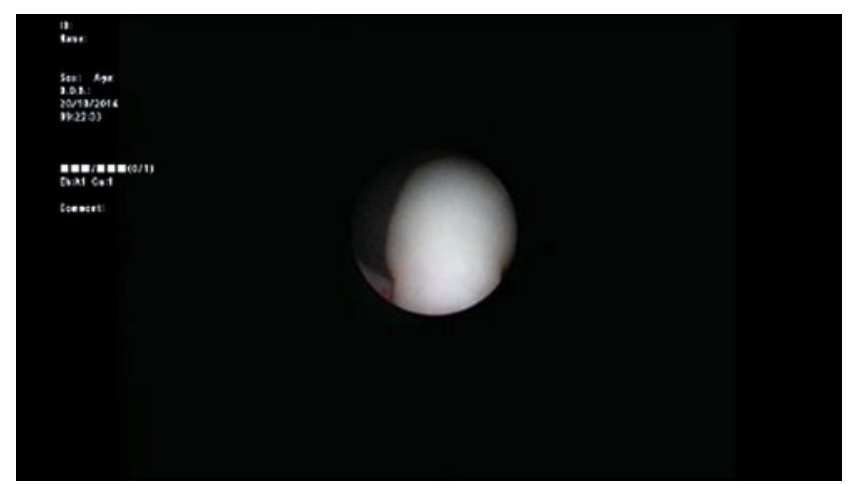

FIG. 2. Urethrocystoscopic image.

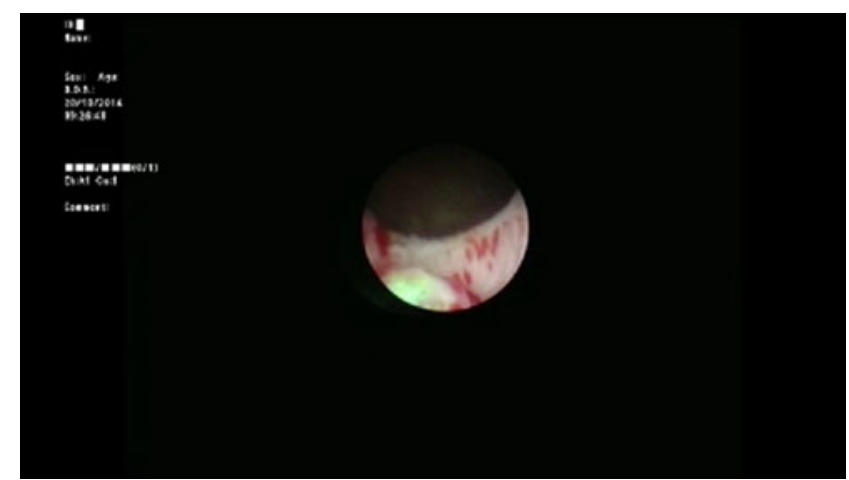

FIG. 3. After ablation.

thral resection and open cystostomy are performed generally to approach the polyps. ${ }^{5}$ The polyp is resected using electrocauterization or cold knife during transurethral treatment. Laser ablation has been recently begun to be used in the treatment. 6

Neodymium: YAG laser has been used in laser ablation until now. ${ }^{6}$ No cases of polyp ablation with Holmium-YAG laser have been reported in the literature to date. Ablation was performed with a newborn cystoscope as the patient was too young and his urethra was thin, and as other treatment choices may have damaged the urethra. The procedure was completed with no complications as Holmium-YAG laser has a thin probe. Open surgery is performed only when the transurethral approach is not possible..$^{5}$

The diameters of pediatric resectoscopes that are used for resection of urethral polyps are 11F-13F (Karl Storz) and 9F (Wolf). The external diameter of the newborn cystoscope that we used in our case was $6 \mathrm{~F}$ (Wolf). A cystoscope that has a smaller external diameter than resectoscopes makes Holmium-YAG laser a good choice, which has a possibility of easy application with the newborn cystoscope on newborns and infants who have particularly thin urethra.

In conclusion, urethral polyps should be considered in the differential diagnosis of hematuria and urinary obstruction in male children. We recommend Holmium-YAG laser for treatment, as it is safe and has a good prognosis.

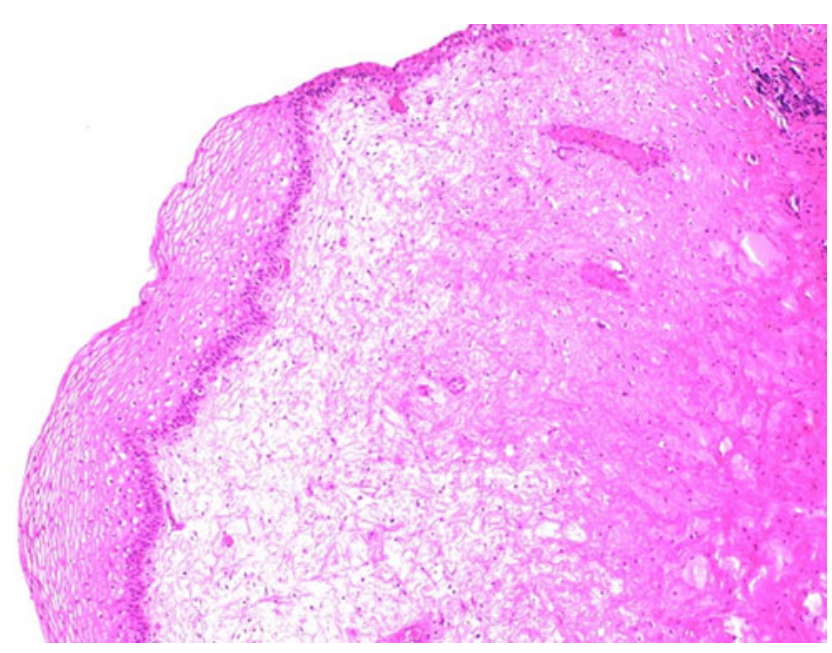

FIG. 4. Pathology analysis "squamous metaplasia." 


\section{Disclosure Statement}

No competing financial interests exist.

\section{References}

1. Walsh PJ, Wiener JS. Urethral polyp presenting in a male infant with hematuria and urinary retention. Urology 1999; 54:921-922.

2. Kearney GP, Lebowitz RL, Retik AB. Obstructing polyps of the posterior urethra in boys: Embryology and management. J Urol 1979;122:802-804.

3. Raviv G, Leibovitch I, Hanani J, et al. Hematuria and voiding disorders in children caused by congenital urethral polyps. Principles of diagnosis and management. Eur Urol 1993;23:382-385.

4. Gleason PE, Kramer SA. Genitourinary polyps in children. Urology 1994;44:106-109.

5. Akbarzadeh A, Khorramirouz R, Kajbafzadeh AM. Congenital urethral polyps in children: Report of 18 patients and review of literature. J Pediatr Surg 2014;49:835-839.

6. Gentle DL, Kaufman RP Jr., Mandell J. Use of neodymium: Yttrium-aluminum-garnet laser for removal of a congenital posterior urethral polyp in a 3-year-old child: A case report and review of the literature. Urology 1996;47:445-447.
Address correspondence to:

Fatih Ozkaya, MD

Department of Urology

Erzurum Regional Training and Research Hospital

Palandoken

Erzurum 25240

Turkey

E-mail: drfatihm@gmail.com

\begin{tabular}{c} 
Abbreviation Used \\
YAG $=$ yttrium-aluminum-garnet \\
\hline
\end{tabular}

Cite this article as: Ozkaya F, Keskin E, Yapanoglu T, Adanur S, Ziypak T, Altay MS, Aksoy Y (2016) Posterior urethral polyp: first Holmium-YAG laser ablation on a 3-month-old infant, Journal of Endourology Case Reports 2:1, 90-92, DOI: 10.1089/cren.2016.0037. 